\title{
A BIODIVERSIDADE MARINHA NOS MUSEUS DE PORTUGAL CONTINENTAL: UMA INTRODUÇÃO
}

\author{
Bruno Pinto
}

Inês Amorim

DOI: https://doi.org//0265 I2/museologia.v7i I 4.18389

\begin{abstract}
RESUMO
O papel desenvolvido pelos museus nas representações dos usos do mar, quer do património marítimo de pendor etnográfico, quer do património científico, articula-se com a evolução dos conceitos de mediação, literacia cultural e científica. Este artigo pretende adotar esta perspetiva na abordagem da história dos museus em Portugal Continental, que estão associados à biodiversidade marinha. Definimos cinco tipologias principais de museus: Museus de História Natural Universitários; Aquários Históricos; Museus Marítimos Etnográficos;Aquários Modernos e Centros de Ciência. Nos exemplos representativos de cada uma destas categorias, contextualizamos a sua origem, os principais eventos ao longo da sua história e a sua relação com outras instituições ligadas ao património marítimo. Observamos, também, que estes museus remontam ao final do século XVIII, mas que nas duas últimas décadas surgiram novos protagonistas, como os centros de ciência e os aquários modernos. Para além disso, também os museus etnográficos abordam hoje a biodiversidade marinha, sinal de uma progressiva abordagem interdisciplinar e de um debate em torno do património natural e cultural associado aos oceanos.
\end{abstract}

\section{PALAVRAS-CHAVE}

Património marítimo, biodiversidade, centros vivos, museus marítimos, oceanos, interdisciplinaridade

\begin{abstract}
The role of museums in representing the uses of ethnographic maritime patrimony, or of the scientific heritage, is articulated with the evolution of the concepts of mediation, cultural and scientific literacy. This article intends to adopt this perspective in approaching the history of museums in Portugal Continental, which are associated with marine biodiversity. We define five typologies main museums: Natural History Museums; Historical Aquariums; Maritime Ethnographic Museums; Modern Aquariums and Science Centers. We representative examples of each of these categories, we contextualize their origin, the main events throughout its history and its relation with other institutions linked to maritime heritage. We also note that these museums date back to the end of the 18th century, but that in the last two decades new protagonists, such as science centers and modern aquariums. Furthermore, also ethnographic museums today address marine biodiversity, a sign of a progressive interdisciplinary approach and a debate on the natural and associated with the oceans.
\end{abstract}

\section{KEYWORDS}

Maritime heritage, biodiversity, living centers, marine museums, oceans, interdisciplinarity

\section{Introdução}

Os oceanos deixaram marcas, inscritas ao longo do tempo, à medida que os nossos antepassados procuraram conhecê-los, interpretá-los e protegê-los, numa perceção muitas vezes idealizada de "terra incógnita".Tais marcas resultam de uma aproximação de diversos atores (por exemplo, pescadores, marinheiros, 
militares, naturalistas, investigadores, etc.), e traduzem-se em diversos tipos de reservatórios de interpretação dos oceanos (Amorim, 2008; Chappé, 2010).

Em geral, os museus têm sido uma das principais plataformas de mediação e valorização deste património associado ao mar ao longo do tempo, evoluindo de meros repositórios de curiosidades para espaços de conhecimento e disseminação de saberes, com um renovado protagonismo estético, de sentido utilitário e educativo (Maria Bolanos, 2002). Para além disso, existem atualmente novos atores que desempenham um papel importante nesta difusão do conhecimento sobre os oceanos, de que são exemplos os centros de ciência. Tal transformação acompanha um movimento de diversidade plural, mobilizando o património cultural e o natural, a transformação de museus como "túmulos" e "armazéns" em "centros vivos” (Semedo, 2004).

Tendo em conta a grande proliferação de instituições dedicadas à manutenção do património marítimo português, vários autores referiram a necessidade do seu levantamento sistemático (e.g. Garrido, 2009; Amorim 2012). Um balanço breve identificou I5I instituições/associações distribuídas ao longo da costa portuguesa, continental e insular, que se consideram guardiãs e dinamizadoras de património marítimo (Sancho Querol, 2009).

Neste artigo, focamos de forma sucinta a história da presença da biodiversidade marinha nos museus em Portugal continental. Assim, definimos cinco tipologias principais de museus associadas aos oceanos: I- Museus de História Natural Universitários; 2- Aquários Históricos; 3- Museus Etnográficos Marítimos; 4 - Aquários Modernos; 5 - Centros de Ciência. Nos exemplos representativos de cada categoria, abordamos o contexto da sua criação, os principais eventos que marcaram a sua história, e a sua relação com outras instituições nacionais e internacionais.

Procuramos, assim, seguir a ordem cronológica da criação destes museus em Portugal. Primeiro, falamos da emergência do património científico dos museus universitários, que foram criados no final do século XVIII e que ganharam novo fôlego nos anos 1970 (Gil, 2002, 2005). Estas instituições são herdeiras dos embrionários gabinetes de curiosidades e ganharam terreno como plataformas de interdisciplinaridade, de práticas museológicas e de reapropriação pública da ciência (Andrade, 20I0). Revisitamos, também, o início dos aquários públicos em Portugal no final do século XIX, associados às viagens oceânicas exploratórias por pioneiros como o Rei D. Carlos (Saldanha, 1980, 1997). Depois, seguimos os museus originalmente de forte pendor etnográfico, em grande medida herdeiros das condições históricas de representação das identidades locais, e que procuram hoje outras formas de mediação de um património ambiental (Leal, 2000; Cabral, 2008; Damasceno, 2010). Olhamos, também, para a história dos aquários modernos como o Oceanário de Lisboa, que apresentam uma maior capacidade de representação de colecções vivas de biodiversidade marinha, atraindo assim um elevado número de visitantes todos os anos. Por último, procuramos abordar a criação dos primeiros centros de ciência no país, a partir de meados dos anos 1990, nos quais se procura introduzir a experimentação como forma de disseminação do conhecimento.

\section{I.I. Museus de História Natural Universitários: Lisboa, Coimbra e Porto}

Os atuais Museus universitários (Museu Nacional de História Natural e da Ciência em Lisboa, Museu da Ciência da Universidade de Coimbra e Museu de 
História Natural e Ciência do Porto/Galeria da Biodiversidade), criados a partir de finais do século XVIII, têm as suas raízes nos gabinetes de curiosidades setecentistas, de iniciativa privada ou pela família Real. Estes acumulavam, ao gosto dos colecionadores, as naturalia e mirabilia, ou seja, as raridades da natureza, dos reinos mineral, vegetal e animal, e no segundo caso, objetos exóticos, maravilhosos, antiguidades (Brigola 2003; Brigola, 2010: I4).

Num segundo momento, o ambiente cultural do lluminismo e a reforma da universidade de Coimbra do século XVIII, a única do país nessa época, justificaram a criação de instituições de iniciativa régia: os Museus de História $\mathrm{Na}$ tural e Jardins Botânicos da Ajuda em Lisboa, e os da Universidade de Coimbra. No primeiro, instalou-se o Gabinete de História Natural de Lisboa (1768), sob a gestão de Domingos Vandelli (I768-1810), que também foi responsável pelo plano do Jardim Botânico de Coimbra, assim como por outras iniciativas nesta cidade e Universidade (Simões et al, 20 I3). Estes museus serviam, num primeiro momento, para o ensino e recreio dos príncipes e da família real, mas também dos alunos de História Natural, no seio da Universidade (Póvoas et al., 2016).

Uma terceira fase correspondeu à criação das Escolas Politécnicas (Lisboa e Porto, em 1837), que receberam os espécimes botânicos, zoológicos e geológicos dos anteriores gabinetes, com funções de apoio pedagógico aos estudos de História Natural (Basto, 1937; Brigola, 2010). Trata-se de uma fase fundamental de desenvolvimento, diferenciado dos museus dedicados a várias especializações científicas (Antropologia, Zoologia, Botânica, Mineralogia, Meteorologia, etc.). Este é resultado quer da multiplicação de expedições ultramarinas quer do envolvimento de Portugal nas exposições universais, que apontavam para o ensino universitário experimental e técnico como condição para o progresso económico (Gil, 2005;Amaral et al, 2013; Ceríaco, 20 I4).

Numa quarta etapa, a reforma universitária de I91 I (associada à instalação da República) criou as Faculdades de Ciências nas universidades então existentes, Lisboa, Porto e Coimbra, sendo que as primeiras absorveram as anteriores Escolas Politécnicas. Em Lisboa, o já existente Museu, sob a tutela da Escola Politécnica e com a designação de Museu Nacional de História Natural desde 1926, estava dividido em três unidades, de acordo com as especializações de que era herdeiro: Geologia, Botânica e Zoologia/Antropologia (Saldanha et al, 20 I5; Gil, 2005). Nas Universidades do Porto e Coimbra, a evolução foi idêntica, com a multiplicação de secções, estando a Antropologia separada da Zoologia (Salgueiro, 2015). A descrição de cada um destes núcleos é impossível de se fazer de forma detalhada. Mas é sabido que o percurso e a notoriedade de cada secção museológica estiveram associadas a homens de ciência de afirmação internacional (Brigola, 2003; Brigola, 2010; Fiolhais, 20I3; Nunes, 2004).

Uma última fase surge após a revolução do 25 de abril de 1974, no âmbito do processo de democratização do país e da evolução do papel das universidades. Articulou-se com a própria evolução da investigação científica que desvalorizou o papel dos anteriores núcleos museológicos frente ao surgimento de centros interativos de ciência, a emergência do conceito museológico e de museus de ciência, aproveitando o quadro de financiamento no âmbito da União Europeia.

Neste contexto, um novo enquadramento legal autonomizou quase totalmente, não sem reservas, os Museus Universitários frente às Faculdades de Ciências, passando para a tutela das Universidades. No caso de Lisboa, fundiram-se os antigos núcleos, regidos por novos estatutos (desde 1978), originando o Museu Nacional de História Natural e o Museu de Ciência da Universidade de Lisboa, e que desde 20II deu origem à Unidade Museus da Universidade de 
Lisboa (Póvoas et al, 2016).

O Museu da Ciência de Coimbra (anteriormente Museu Nacional da Ciência e da Técnica Doutor Mário Silva, 1971-2004), esboçado desde 2005 como "Museu do Conhecimento", foi inaugurado em 2006, numa primeira fase definido como uma configuração do futuro Museu da Ciência (Duarte, 2007). Sediado num dos múltiplos edifícios (laboratório Químico) que alberga as heranças dos sucessivos gabinetes (Simões, 2013), prepara-se para a recuperação de outros edifícios emblemáticos que darão fôlego a projetos de exibição de antigas coleções. Uma das suas maiores valias é o Museu Digital, apoiado numa forte equipe de investigação, o qual pretende disponibilizar representações de exemplares museológicos on line (Pires \& Pereira, 2010).

Já o atual Museu de História Natural e Ciência da Universidade do Porto foi fundado em 1996, de acordo com os núcleos pré-existentes que tinham adotado o nome de figuras eminentes da investigação, docência e vida pública nacional (Monteiro et al, 20 I0). Desde 20I I, a aprovação dos estatutos coloca-o sob a cotutela da Reitoria da Universidade do Porto e da Faculdade de Ciências. Um novo discurso expositivo, sob consultoria do Professor Jorge Wagensberg (1948-2018), responsável pelo museu CosmoCaixa (o primeiro Museu de Cência interativa de Espanha), em 198I, levou a que a Universidade do Porto criasse dois núcleos de uma concepção global: o Museu de História Natural e Ciência (Evolução) e a Casa da Biodiversidade "Sophia Andersen” (Diversidade). A abordagem conceitual dos dois museus partiu da chamada Museologia Total (Wagensberg, 2005) filosofia museográfica que - neste caso - utiliza uma linguagem baseada em metáforas museográficas para explicar a história da evolução biológica (Santos, 2016).

Os atuais Museus de História Natural e Ciência têm a incumbência de despertar no público um interesse pela cultura científica e de acautelar o futuro dos bens culturais que herdaram (princípios assumidos na declaração de Halle, 2000 e pela rede UMAC - University Museums and Collections criada também em 2000, no âmbito do International Council of Museums; http://umac.icom.museum/). Abordam diversas áreas, desde a geodiversidade e biodiversidade à história das ciências naturais e às atividades de investigação nestas áreas (Delicado, 2006). São espaços, em simultâneo, de contemplação estética e de discussão filosófica de conhecimento para públicos diversificados. Os desafios que enfrentam são comuns a outros Museus de Ciência, nomeadamente como espaços de produção e reprodução da própria ciência, isto é, de criação de conhecimento científico, investigação, e de formação de cientistas e de ensino No entanto, não conseguem cumprir a maioria destes objetivos, por motivos de natureza financeira, por hesitações na definição de tutelas (universidades ou outras instituições), e pela dificuldade em acertar redes de colaboração entre si (Delicado, 2008).

Sublinhe-se que as coleções de biodiversidade marinha existentes nestes museus, acumulam milhares de espécies (peixes, crustáceos, moluscos, plantas marinhas), que animam exposições temporárias e são alvos de inventariação, mas que criam enormes preocupações de conservação e de reconhecimento. São majoritariamente provenientes dos núcleos de zoologia e botânica (plantas marinhas), mas distribuem-se um pouco por todos os núcleos herdados. Alguns estudos de pormenor conseguem identificar a sua proveniência (nacional e internacional) e o seu valor quantitativo (Ceríaco, 20I4; Cunha, 2010, 20I2). Noutros casos, foram alvo de grande divulgação pela espetacularidade dos espécimes. Por exemplo, tal aconteceu em 2010, no âmbito do levantamento das coleções científicas pertencentes à Universidade de Coimbra, em que se encon- 
traram 68 exemplares do século XVIII dos peixes do Brasil (Simões et al, 20I3).

Considere-se, finalmente, que grande parte das espécies, muitas desconhecidas, encontram-se hoje em dia nas coleções dos museus e o seu conhecimento é essencial para avaliar as perdas de biodiversidade atuais (Costello et al., 20I3; Strasser, 20I0). Mesmo levantando-se problemas de identificação e categorização das espécies (Carvalho, 20I4), os resultados desta inventariação da biodiversidade marinha da costa continental portuguesa, dos anteriores espaços coloniais, ou mesmo da Europa, é um contributo importante para alimentar bases de dados internacionais (por exemplo, Global Biodiversity Information Facility (http://www.gbif.org/) ou a Fish Barcode of Life (FISH-BOL, http://barcoding. si.edu/AllFish.htm), iniciativas que todos os Museus de Ciência pretendem disponibilizar nas respetivas plataformas de História Natural Digital). Este é, muito provavelmente, um dos grandes desafios para o futuro.

\section{I.2. Aquários Históricos: o Aquário Vasco da Gama}

No final do século XIX, Portugal vivia um período conturbado da sua política internacional pela disputa de territórios africanos com Inglaterra, que viria posteriormente a perder (Ramos, 20I2). Nesse contexto, e como forma de promover a sua imagem internacional de país com uma forte ligação ao mar, a Sociedade de Geografia de Lisboa propôs um programa de eventos para celebrar os 400 anos da viagem de Vasco da Gama à Índia, que foi apoiado pelo Governo Português (Costa, 1918, 1922). Para liderar o processo de construção de um aquário público, que servisse de testemunho a esta celebração, foi escolhido Albert Girard. Este engenheiro civil e naturalista do Museu de História Natural, de ascendência francesa, ajudou o Rei D. Carlos nas suas expedições oceanográficas, tornando-se mais tarde o curador das colecções zoológicas Reais (Saldanha, 1980, 1997). Girard visitou outros aquários públicos e estações de biologia marinha em países europeus como a França, Holanda e Inglaterra, procurando assim conhecimento técnico que escasseava a nível nacional (Choffat, 1916; Kofoid, 1910; Sociedade Geografia, 1897, 1899).

Depois de vários atrasos, o aquário foi inaugurado a 20 de Maio de 1898 , ainda inacabado, e cedo apresentou sinais de rápida degradação: nos seus primeiros anos de existência, houve aquários que se quebraram, diversos problemas no sistema de captação, armazenamento e renovação de água, elevada mortalidade de peixes, etc. O ritmo acelerado de construção e a falta de conhecimentos na instalação de aquários ajudam a explicar algumas destas deficiências (Diário llustrado, I898; Girard, 1907). Em 1901, o Governo colocou o aquário sob administração da Marinha, sendo esta a instituição que o administra ainda hoje (Costa, I918; Silva, I901).

Oito anos depois, a gestão foi cedida temporariamente à Sociedade Portuguesa de Ciências Naturais, que modificou as instalações de modo a integrar uma estação de biologia marinha. Assim, a investigação científica tornou-se a prioridade do aquário, cooperando com investigadores do Museu de História Natural/Universidade de Lisboa e técnicos da Comissão das Pescarias (Costa, 1918;Athias, 1942). O aquário desenvolveu pesquisas a bordo dos navios "Cinco de Outubro" e "Albacora" em regiões como Portugal continental, o arquipélago da Madeira, Casablanca, Gibraltar e as Ilhas Canárias. Os temas estudados eram diversificados e incluíam a flutuação dos stocks de sardinha, a sobrepesca, o plâncton, as correntes marinhas, a qualidade da água, etc. (SMAS, 2002).

Em 1940, a construção da avenida marginal Lisboa - Cascais ditou a de- 
molição de um terço do aquário, sendo a estação de biologia marinha deslocada para outras instalações acerca de 10 km (Cais do Sodré, Lisboa).Após esta mudança, a gestão pouco cuidada do aquário e a sua suposta degradação ditaram a decisão da Marinha de o separar legalmente da estação de biologia marinha em 1950 (Possante, 1949; Ramalho, 1942). Nas décadas seguintes, o aquário Vasco da Gama foi recuperado e restaurado, tendo sido também construídos secções do aquário . Com a cedência de terrenos da Câmara de Oeiras (nos arredores de Lisboa) em 1976, foram criados novos espaços de exposição e acolhidos outros animais (por exemplo, focas e otárias). É, também, de registar a cooperação com a Universidade de Lisboa entre 1976 e 1986 no desenvolvimento da aquacultura de espécies como o linguado, o robalo e a enguia (Caseiro, 1998; Leandro, 2003). Depois de ultrapassada uma fase de indefinição sobre o seu futuro, em 1998, com o surgimento do Oceanário de Lisboa, este aquário centenário continua a apresentar atualmente uma vasta coleção de aquários e coleções de animais (Pinto \& Costa, 2018). O seu espólio também inclui instrumentos, exemplares biológicos e documentos do Rei D. Carlos, que o aquário recebeu em 1935 (Caseiro, 1998; Leandro, 2003).

No que diz respeito às ligações entre o aquário e outras instituições nacionais, e para além dos vínculos óbvios com a Sociedade de Geografia, a Marinha Portuguesa e a Sociedade Portuguesa de Ciências Naturais, as mais relevantes têm sido com o Museu Nacional de História Natural / Universidade de Lisboa e a Comissão de Pescas. Esta cooperação focou sobretudo a troca de materiais para exposições, o uso do aquário para investigação e ensino, e pessoal técnico que circulou entre estas três instituições (Costa, 1922). A nível internacional, provavelmente a mais relevante foi a ligação ao Conselho Internacional para a Exploração do Mar (CIEM) entre 1920 e 1938, e depois de 1947, o que ajudou a estimular a investigação marinha a nível nacional (Pinto, 2017).

Hoje em dia, este aquário é visitado por cerca de 56000 pessoas por ano, das quais $35 \%$ são relativas a visitas escolares (dados cedidos pelo Aquário Vasco da Gama). Para além das suas funções de comunicação de ciência, coopera regularmente com diversas instituições de investigação, continuando assim a ter um papel no desenvolvimento das ciências marinhas em Portugal (Leandro, 2003).

\section{I.3. Museus Etnográficos Marinhos: o Museu Marítimo de Ílhavo}

O Museu Marítimo de Ílhavo, situado na sede do concelho de Ílhavo na costa noroeste de Portugal, encarna um processo museológico que atravessa todo o século XX, evoluindo para um espaço de interesse nacional (Peralta, 2007). Inseriu-se num projeto de caráter regional que remonta aos finais do século $\mathrm{XIX}$, e que se enquadra na visão etnográfica que perpassou Portugal. Esta foi marcada pela necessidade de recolha de iconografia, objetos e tradições populares em risco, frente à civilização industrial e às crises políticas e econômicas dos inícios do século XX (Garrido \& Lebre, 2007; Sarmento, 2008). O museu foi fundado por Rocha Madahil (1893-1969), que era conservador do arquivo e museu de arte da Universidade de Coimbra, apoiado por Américo Teles (1930-1989), oficial principal dos Correios do Palácio da Bolsa do Porto, e por uma Comissão Municipal Administrativa formada por elementos da elite local (Madahil, 1934). Na sua planificação inicial (1920-1936), propôs a criação de várias secções temáticas (ligadas ao mar e à ria de Aveiro), um arquivo e uma biblioteca regional, que apontavam para a construção de um edifício adequado, enquanto os Paços do Concelho e outros espaços se apresentavam como provisórios.Apoiou-se em figuras 
de prestígio local (fundadores e organizadores, comissões formais e informais, e, desde 194I, no Grupo de Amigos do Museu), num entusiástico regionalismo plasmado em exposições temáticas que promoviam a identidade dos ilhavenses, as suas relações ao mar e a atividades locais (cerâmica e vidro da fábrica da Vista Alegre) (Garrido \& Lebre, 2007).

Este período de institucionalização de apoios (entre os quais recorrendo a outros Museus Etnográficos, como o da Póvoa de Varzim), reivindicou novos edifícios (Garrido \& Lebre, 2007) ao pretender alargar as representações regionais às "artes nacionais", com a entrada no Museu de pinturas de autores de nomeada. Este "rumo a um novo Museu", de 196I-1989 (Garrido \& Lebre, 2007) prenuncia a definitiva maritimização do Museu, ou seja, de construção de uma identidade marítima, propondo-se, já em 1967, a mudança de sua designação para Museu Marítimo e Regional de Ílhavo (Garrido \& Lebre, 2007). O novo edifício, iniciado em 1972, vivendo hesitações em termos de financiamento, organizou exposições de índole nacional, mas marcadamente inspiradas pelas representações marítimas da Ria de Aveiro e da faina no mar (Garrido \& Lebre, 2007). Nos anos 1970, em torno do estudo das suas coleções (por exemplo, de algas, conchas, barcos, etc.) estabeleceu ligações a instituições nacionais e internacionais, como o Instituto e Jardim Botânico da Universidade de Coimbra, o Instituto de Botânica Dr. Gonçalo Sampaio da Universidade do Porto, bem como a Jacques Cousteau e ao Museu Oceanográfico do Mónaco (Teles, 20I2).

O período de 1990 a 1999 foi marcado pelos "homens do mar" da época de ouro da faina da pesca longínqua do bacalhau, envolvendo contatos com empresas de pesca locais, com colecionadores, museus e figuras experientes naquela atividade (Garrido \& Lebre: 2007). O video "À Glória desta Faina" ( 1989), a exposição permanente "Faina Maior- Pesca do bacalhau à linha" (1992), e a reconstituição de um lugre bacalhoeiro e todo o seu universo, dinamizaram um novo projeto museológico. Este envolveu a comunidade regional, nacional e internacional, nomeadamente com a chegada ao porto de Aveiro do barco bacaIhoeiro Creoula que, em 1998, viajou até S. John, capital da Terra Nova.

À reconfiguração do edifício, juntaram-se o núcleo do navio-museu S. André (arrastão da frota portuguesa do bacalhau, construído na Holanda, em 1948 , por encomenda de uma empresa de Aveiro), o farol da praia da barra e o casario policromático da Gafanha. Logo em 200 I, o Museu e o seu projeto arquitetónico ganhou vários prêmios nacionais e internacionais, que o colocaram na lista internacional dos museus de arquitetura (Garrido \& Lebre, 2007).

Já neste contexto, o discurso museológico mudou: em vez de ser um museu marítimo como lugar de culto do passado, tornou-se um "museu do mar", ou seja, um lugar de memória dinâmico e carismático (Garrido, 20I4). Recusou replicar a monumentalidade épica dos museus marcados pela ideologia formulada em finais do século XIX, das armadas e nacionalismos imperiais, para sinalizar a depredação dos recursos marinhos. Foi este o tema que o Museu incluiu no seu projeto desde que passou a ter um património biológico extraordinário: um aquário de bacalhaus, que foi aberto ao público em janeiro de 2013 (Argos, 2013). Juntamente, assumiu a ideia de fazer do Museu um lugar de memória sem perder o sentido da construção identitária ou das suas ficções (Peralta, 2006). Por isso, organizou a exposição "Caixa da memória - Tributo aos homens que foram ao bacalhau", um registo de instalação e fotografia, que viajou por portos de pesca portugueses, adaptando a cada localidade os rostos e nomes dos pescadores locais (Garrido \& Lebre, 2008). Em simultâneo, o programa ancorou-se na investigação, exposição, educação e comunicação cultural (CIEMar-lílhavo - 
Centro de Investigação e Empreendedorismo do Mar), tornando-se "casa de cultura do mar", imagem dinamizadora e explicitada no seu nome, Museu Marítimo de Ílhavo: museu, aquário, investigação.

\section{I.4. Aquários Modernos: o Oceanário de Lisboa}

Para celebrar os 500 anos da viagem de Vasco da Gama à Índia, o Governo Português organizou uma exposição mundial na parte oriental de Lisboa, em que este aquário era um dos seus ex-libris (Parque Expo'98, 1999). A Expo'98, com o tema "Oceanos, um património para o futuro" decorreu entre 22 de Maio e 30 de Setembro de 1998 e tinha como um dos seus objetivos uma reaproximação de Portugal ao mar (Decreto-lei 81/86, 22/I I//986; Martins, 2016; Parque Expo'98, 1999).

O Oceanário de Lisboa foi projetado pela equipe do arquiteto norte-americano Peter Chermayeff, tendo sido construído numa parceria entre empresas portuguesas e internacionais. De fato, a instalação e manutenção deste aquário implicaram um desenvolvimento técnico no país em áreas como a aquariologia e a museologia (Pinto, 20I8).Atualmente, a sua exposição permanente inclui cerca de 500 espécies diferentes, distribuídas por quatro habitats diferentes, e que representam os oceanos Atlântico Norte, Antártico, Pacífico Temperado e Índico Tropical. Estes estão separados do aquário central, o oceano global, que é visível através de quatro grandes janelas de acrílico (Oceanário de Lisboa, 20 I I, 20I5).

A história do Oceanário carateriza-se pelas suas exposições permanentes e temporárias, pelo lançamento do Programa de Educação, logo em 1999, e pela colaboração de nível nacional e internacional com instituições congêneres, de investigação e acadêmicas. Para além disso, esta instituição tem apoiado diversos projectos de conservação de Natureza (Oceanário de Lisboa, 20I I, 20I5). É de destacar a renovação de conteúdos desde 2006 através das exposições "Bastidores do Oceanário" ou "Um Planeta. Um oceano." (Oceanário de Lisboa, 20ll). Numa fase posterior, foram também realizadas várias exposições fotográficas de Natureza no interior ou na proximidade do Oceanário. Em abril de $201 \mathrm{I}$, foi finalizada a expansão deste aquário com a construção de um novo edifício (Edifício do Mar), que integra atualmente as bilheteiras, um auditório, um restaurante, um espaço dedicado a exposições temporárias e outros serviços. (Oceanário de Lisboa, 20I4).

Mais recentemente, também ocorreram mudanças importantes a assinalar. Em primeiro lugar, foi inaugurada em 2015 a exposição temporária "Florestas submersas" assinada pelo japonês Takashi Amano, que atraiu não só milhares de visitantes nacionais mas também visitantes internacionais que admiram o seu trabalho (Oceanário de Lisboa, 20I5). Foi, também, no decorrer deste ano que - Oceanário foi privatizado com a garantia de manutenção de serviço público, tendo como acionista a Sociedade Francisco Manuel dos Santos. Em março de 2017, esta Sociedade criou a Fundação Oceano Azul, na qual o Oceanário hoje se integra, e que tem como principal objetivo contribuir para a conservação e uso sustentável dos oceanos (Fundação Oceano Azul, 2018).

Em 2018, ano em que se celebra o seu $20^{\circ}$ aniversário, o Oceanário é o maior aquário do país e um dos mais importantes da Europa, recebendo mais de um milhão de visitantes por ano (Oceanário de Lisboa, 20 I I, 20 I 5). É visto como um elemento-chave para comunicar sobre o ambiente marinho a nível nacional, tendo também impacto a nível internacional pelo fato de cerca de $60 \%$ dos seus visitantes serem de outros países (Oceanário de Lisboa, 2015; Pinto \& Costa, 
2018). Para além disso, tem promovido um programa de educação ambiental praticamente desde o início do seu funcionamento e integra várias iniciativas de literacia sobre o oceano (Oceanário de Lisboa, 20 I I, 20 I5). No que diz respeito a parcerias, o Oceanário colabora regularmente com instituições nacionais tais como a Estrutura de Missão da Extensão da Plataforma Continental Portuguesa (EMEPC), a Agência Nacional para a Cultura Científica e Tecnológica (Ciência Viva) e o aquário Vasco da Gama (Oceanário de Lisboa, 20II, 20I5).

\section{I.5. Centros de ciência: o Centro Ciência Viva do Algarve}

Em meados dos anos 1990, na sequência da criação em Portugal do novo Ministério da Ciência e Tecnologia, e a nomeação do investigador e professor universitário José Mariano Gago para tutelar esta pasta, a comunicação de ciência ganhou maior protagonismo nas políticas públicas nacionais (Costa et al., 2009; Delicado, 2010).Assim, foi estabelecida em 1996 a "Agência Nacional para a Cultura Científica e Tecnológica - Ciência Viva" como uma unidade do Ministério da Ciência e Tecnologia dedicada à promoção da cultura científica (Granado \& Malheiros, 2015). Após a fundação desta agência, têm sido estabelecidos centros de ciência em várias regiões do país como novos espaços museológicos, caracterizados pela busca da experimentação e interatividade.Assim, estes centros têm o principal objetivo de "promoção e divulgação da cultura científica e tecnológica através de acções dirigidas ao público, com especial vocação para uma actuação junto da comunidade juvenil" (Despacho 8890/2002).

O primeiro centro de ciência a ser criado em Portugal foi o Centro Ciência Viva do Algarve, tendo sido inaugurado a 3 de Agosto de 1997. Esta iniciativa partiu da Associação para a Divulgação de Ciência e Tecnologia (ADCT), tendo contado com o apoio do Ministério da Ciência e Tecnologia. $O$ centro foi estabelecido na Antiga Central Eléctrica de Faro, um edifício histórico que fica junto à Ria Formosa (CCV Algarve, 1998, 1999; Delicado, 2010). Desde o início do seu funcionamento, este centro dedica-se a temas relacionados com o mar, tendo acolhido exposições, módulos interativos, aquários e diversas atividades. A sua primeira exposição permanente focava a importância do sol na vida dos mares, tendo também diversas espécies faunísticas e atividades tais como laboratórios de aquários (CCV Algarve, 1998, 1999).

Em 2003, foi estabelecido um protocolo de colaboração com a organização não governamental Ocean Technology Foundation (Universidade Connecticut, EUA) para desenvolver a exposição "No profundo oceano". O elemento central desta exposição é a Ocean Base One, uma estrutura subaquática que é semelhante a uma estação espacial. Com a remodelação total deste centro, a sua exposição permanente passou a ter o mar como seu tema principal a partir de meados de 2006, incluíndo áreas temáticas como a evolução dos oceanos e a biodiversidade. Foi, também, adquirido um aquário interactivo (designado por "apalpário"), em que os visitantes são convidados a tocar em algumas das espécies aquáticas que ocorrem na Ria Formosa (CCV Algarve, 20I I). As instituições responsáveis por este centro de ciência têm mudado ao longo da sua história, sendo atualmente a Agência Ciência Viva, a Universidade do Algarve, a C.M. Faro e a C.M. Albufeira (CCV Algarve, 20I8). De acordo com um estudo sobre a visitação a este centro entre 2012 e 2015 , o número médio anual de visitantes foi cerca de 30000 pessoas por ano, que se caracteriza por uma elevada percentagem de público com formação de ensino superior (Garcia et al., 2016). 
Atualmente, a Rede Nacional de Centros Ciência Viva é constituída por 20 centros, distribuídos ao longo do território português (Ciência Viva, 2018). Esta rede foi construída, geralmente, através de parcerias entre a Agência e atores locais tais como municípios, universidades e/ou centros de investigação, em que cada centro adotou um ou mais temas de relevância local para as suas exposições e atividades. Para além da ligação direta do Centro de Ciência do Algarve ao mar, o Centro de Ciência de Lagos aborda temas relacionados com os Descobrimentos Portugueses e a navegação marítima, o Centro de Ciência de Tavira integra os temas da água e da poluição, o Centro de Ciência do Expolab em S. Miguel (Açores) tem uma secção sobre biologia marinha e o Centro de Ciência da Galeria da Biodiversidade (Porto) também inclui espécies marinhas.

\section{Considerações finais}

Um dos objectivos do presente trabalho foi o de apresentar sucintamente a história de exemplos representativos de museus associados à biodiversidade marinha em Portugal continental e como se cruzam áreas disciplinares, num percurso que envolve recursos oceânicos e modos de os conhecer, ao longo do tempo, através do ensino, investigação e divulgação científica. Desta forma, pretendeu-se esboçar quais os principais tipos de museus sobre esta temática, $\mathrm{e}$ também contar uma história mais global que começou no final do século XVIII e se prolonga até à atualidade (ver tabela I de resumo em anexo).

No caso dos museus de história natural universitários, a sua função inicial de repositórios das colecões de biodiversidade foi redefinida para serem espaços de comunicação de ciência que procuram a inovação. Assim, as suas linhas de ação tentam articular a gestão de coleções científicas, por vezes consideradas demasiado estáticas frente ao desenvolvimento tecnológico, e a um discurso museológico contemporâneo (Martinez, 20I3). É de notar que as coleções associadas à biodiversidade marinha têm sido pouco estudadas, apesar de serem vistas como um património científico importante para a compreensão de ameaças como a sobre-exploração de recursos naturais ou as alterações climáticas. $\mathrm{Na}$ verdade, as suas multivalências são um desafio na mediação de todo um legado, com caráter histórico e natural, na sua preservação e conservação frente à mudança de paradigma expositivo atual. Tal justifica-se porque um museu é, em simultâneo, um local de contemplação estética e de discussão filosófica do conhecimento. Ao quererem adaptar-se às necessidades da sociedade, entre o lazer e a aprendizagem, precisam se reinventar. Atualmente, parecem fazê-lo num contexto internacional de renovação dos museus universitários, criadores de diálogos entre ciência, arte e emoções, em que a tecnologia é um expediente para a criação de plataformas digitais. Veja-se o exemplo do Museu de História Natural de Londres, que lidera um consórcio de 20 organizações europeias, incluindo universidades, empresas privadas, museus e jardins botânicos na criação de uma pesquisa integrada que procura desenvolver três elementos estrategicamente importantes: o acesso, uma rede de museus e uma pesquisa colaborativa entre instituições (Projeto Synthesys, Natural History Museum strategy to 2020, disponível em http://www.nhm.ac.uk/about-us/our-vision-strategy.html).

Ao serem vistos como museus reconhecidos pelo ICOM (International Council of Museums), duas comissões interessam aos museus universitários - o CIMUSET (International Committee for Museums and Collections of Science and Technology) e o NATHIST (Natural History International Committee for Museums and Collections of Natural History). $O$ primeiro inclui, também, os mais recentes 
centros de ciência, no sentido de popularizar a ciência e promovê-la entre o público, principalmente o mais jovem. $O$ segundo, diz respeito à conservação da diversidade biológica nas colecções dos museus assim como do ambiente natural, promovendo estudos científicos do património natural e a educação do público em geral. As dificuldades maiores estarão nos largos recursos financeiros e humanos exigidos por equipes multidisciplinares. Mas a natureza das tutelas também continua a ser objeto de discussões nada consensuais. Finalmente, o discurso narrativo também não colhe unanimidades, à procura da sua natureza, se um museu de ciência e técnica é um museu "total" (Wagensberg, 2005).

No que diz respeito ao exemplo apresentado do aquário Vasco da Gama, vemos também mudanças nos objetivos da sua gestão ao longo da sua história. Assim, o que era inicialmente uma infraestrutura com o principal propósito de popularização da ciência tornou-se no início do século $X X$ a principal estação de biologia marinha do país. Nos anos 1950, e na sequência de uma redução de cerca de um terço da dimensão do aquário original, a investigação deixou de ser prioritária, voltando assim a dar maior importância à divulgação da ciência ao público (Pinto, 2017; Rollo et al., 20l4). Nas décadas seguintes, este aquário foi sendo ampliado e remodelado de modo a poder albergar uma maior diversidade de animais na sua coleção. Hoje em dia, este aquário procura a sua renovação tirando partido do seu património histórico e desta sua ligação ao início da investigação em biologia marinha em Portugal.

Em comparação com outros países da Europa como Inglaterra, as condições durante parte do século $X X$ não foram favoráveis ao crescimento da disseminação da ciência em Portugal.Assim, o estabelecimento de um regime ditatorial entre 1926 e 1974, a falta da liberdade de expressão, o baixo nível de literacia nacional e o isolamento político do país durante este período estão relacionados com um certo atraso neste domínio (Costa et al., 2009). No entanto, algumas instituições como os Aquários Vasco da Gama e Aquário da Foz ou os Museus de História Natural de Universidades continuaram as suas atividades. No caso dos museus etnográficos, estes assumiram um papel preponderante na medida em que entroncavam numa doutrina social mais ampla, um ideário nacionalista que usava os museus como suportes de um ambiente de paz e vazio de conflitos (Damasceno, 2010). Nem sempre assim ocorreu, mas é certo que se tornaram arenas de afirmação de causas e de culto pelo passado, de exaltação de valores baseados no trabalho - pelo que os museus ligados ao mar não são exceção.

Por outro lado, e sobretudo a partir dos anos 1980, a vertente etnográfica acrescentou uma leitura adicional, atenta à diversidade cultural e ao papel desempenhado pela Humanidade no ambiente natural (Morris, 20 I I). No caso do Museu Marítimo de Ílhavo, sublinhe-se o fato de ter na base da sua criação um movimento que integrou uma elite cultural local e cidadãos comuns (Grupo de Amigos do Museu). Este exemplo demonstra como se procurou acrescentar, à dimensão da memória sobre a pesca e às evocações nostálgicas de uma ideia de perda inexorável (fim da pesca, do império marítimo, etc.) a disseminação da pesquisa científica relacionada com a pesca do bacalhau em particular (Peralta, 2009). Foi, também, nesse sentido que este museu incorporou outra narrativa, ao dispor de um aquário com bacalhaus a partir de 2013, como um recurso educativo que pretende ilustrar diversas problemáticas ambientais exemplificadas por esta espécie (e.g. sobre-exploração).

Existem outros museus em Portugal em que a etnografia e história coexistem com as ciências marinhas. Por exemplo, no museu do Mar em Cascais, é dada relevância aos recursos marinhos, à arqueologia marinha, ao início das 
expedições oceanográficas em Portugal feitas pelo Rei D. Carlos, mas também às artes de pesca tradicionais e aos testemunhos dos pescadores da região (Museu do Mar, 2018). Contudo, na sua maioria, são museus de caráter regional com dificuldades de sobrevivência financeira, não obstante o sentido patrimonial identitário (associação às ocupações ligadas ao mar). $\bigcirc$ número pode ser extraordinariamente impressionante se se incluírem instituições/associações, instaladas ao longo da costa portuguesa, continental e ilhas, que, embora nem sempre associadas à museologia, se consideram guardiãs e dinamizadoras de património marítimo (e mesmo fluvial). Incluem unidades ligadas à pesca marítima e fluvial (baleia, polvo ou outras espécies; técnicas e trabalho a bordo e em terra), exploração de sal (ecomuseus), conservas de peixe (indústria conserveira), navegação e construção naval (estaleiros, coleção de embarcações, originais, réplicas e miniaturas) (Sancho Querol, 2009).

Foi, também, nos anos 1980 que se registou um crescimento da disseminação da ciência em Portugal. Por exemplo, o aumento da presença da ciência nos livros e na imprensa nacional é uma das manifestações desse crescimento (Costa et al., 2009). Como referido anteriormente, a criação do primeiro Ministério da Ciência e Tecnologia em Portugal em meados dos anos 1990 também é um sinal da maior importância política dada a estas áreas. Através de parceiras entre a Agência Ciência Viva e câmaras municipais, universidades, associações científicas e centros de investigação, foi possível estabelecer cerca de 20 centros de ciência localizados em diversas regiões do país. Mais concretamente, alguns destes centros têm uma relação direta com as ciências marinhas, possibilitando assim a sua aprendizagem de uma forma mais interativa do que em museus tradicionais (Delicado, 2010).

O estabelecimento do Oceanário de Lisboa, que foi inaugurado em 1998, vem também trazer um novo tipo de infraestrutura ao país. Distinguindo-se dos aquários existentes em Portugal naquela época, este Oceanário tem tanques suficientemente grandes para albergar animais de grande porte (Kisling, 200 I; Oceanário de Lisboa, 20II, 20I5). Para além disso, a maior dimensão do seu espaço expositivo permite uma representação mais fiel e detalhada de ecossistemas marinhos oceânicos, à semelhança do que se passa noutros oceanários construídos noutras regiões do mundo (Brunner, 2003; Kisling, 200 I; Salgado \& Marandino, 20 I4). Devido à sua grande popularidade, tem um elevado número de visitantes tanto portugueses como estrangeiros, sendo por isso considerado um dos elementos fundamentais para comunicar sobre ciências marinhas em Portugal (Pinto \& Costa, 2018).

Por último, se a informação disponível desde o novo milénio sugere que a população portuguesa tem um interesse relativamente baixo em ciência e tecnologia, quando comparado com outros países da União Europeia (Comissão Europeia, 200 I, 2005, 2010), estes dados tornam-se um desafio para os espaços de mediação estudados. Por um lado, cerca de $35 \%$ dos entrevistados portugueses em 2010 afirmaram não estar interessados em descobertas científicas e desenvolvimentos tecnológicos, sendo o valor médio dos países na União Europeia (EU26) de cerca de $20 \%$. Por outro lado, é de referir que a área das ciências marinhas é considerada de elevada produtividade científica em Portugal (FCT, 20I5), que atingiu o $17^{\circ}$ lugar no ranking mundial entre 2010 e 2014 (UNESCO, 2017). Desta forma, os novos e tradicionais museus, que incluem a biodiversidade marinha, continuarão a ser atores importantes na disseminação científica desta área, a uma escala nacional e internacional e no cruzamento das humanidades e das ciências naturais, numa contínua e renovada valorização do 
património cultural e natural.

Anexo I

\begin{tabular}{|c|c|c|c|c|c|}
\hline Identificação & $\begin{array}{l}\text { Tipologia } \\
\text { de Museu }\end{array}$ & $\begin{array}{l}\text { Ano(s) } \\
\text { de } \\
\text { abertu- } \\
\text { ra }\end{array}$ & $\begin{array}{l}\text { Contexto(s) } \\
\text { de criação }\end{array}$ & Fundadores & $\begin{array}{l}\text { Gestores } \\
\text { atuais }\end{array}$ \\
\hline \begin{tabular}{|l|} 
Museus Histó- \\
ria Natural \\
Lisboa / Porto / \\
Coimbra
\end{tabular} & $\begin{array}{l}\text { Museu } \\
\text { História } \\
\text { Natural }\end{array}$ & $\begin{array}{l}\text { Finais } \\
\text { do séc. } \\
X V I I I\end{array}$ & $\begin{array}{l}\text { Reforma da uni- } \\
\text { versidade, llumi- } \\
\text { nismo, Colecio- } \\
\text { nismo }\end{array}$ & $\begin{array}{l}\text { Figuras } \\
\text { associadas às } \\
\text { Academias e } \\
\text { Universida- } \\
\text { des e família } \\
\text { Real Portu- } \\
\text { guesa }\end{array}$ & $\begin{array}{l}\text { Universida- } \\
\text { des Lisboa, } \\
\text { Porto e } \\
\text { Coimbra }\end{array}$ \\
\hline $\begin{array}{l}\text { Aquário Vasco } \\
\text { da Gama } \\
\text { (Lisboa) }\end{array}$ & $\begin{array}{l}\text { Aquário } \\
\text { histórico }\end{array}$ & 1898 & $\begin{array}{l}\text { Exposição sobre } \\
\text { o mar (Lisboa) } \\
\text { para celebrar } \\
\text { os } 400 \text { anos da } \\
\text { viagem de Vasco } \\
\text { da Gama }\end{array}$ & $\begin{array}{l}\text { Sociedade } \\
\text { Geografia } \\
\text { Lisboa }\end{array}$ & $\begin{array}{l}\text { Marinha } \\
\text { Portuguesa } \\
\text { (Ministério } \\
\text { Defesa Na- } \\
\text { cional) }\end{array}$ \\
\hline $\begin{array}{l}\text { Museu Maríti- } \\
\text { mo Ílhavo }\end{array}$ & $\begin{array}{l}\text { Museu et- } \\
\text { nográfico }\end{array}$ & 1937 & $\begin{array}{l}\text { Valorização do } \\
\text { mundo marítimo } \\
\text { local e regional } \\
\text { em risco, frente } \\
\text { ao progresso } \\
\text { industrial }\end{array}$ & \begin{tabular}{|l|} 
Comissão \\
Municipal \\
Administra- \\
tiva, Rocha \\
Madahil, \\
Américo \\
Teles \\
\end{tabular} & $\begin{array}{l}\text { Câmara } \\
\text { Municipal de } \\
\text { Ílhavo }\end{array}$ \\
\hline $\begin{array}{l}\text { Centro Ciência } \\
\text { Viva Algarve } \\
\text { (Faro) }\end{array}$ & $\begin{array}{l}\text { Centro de } \\
\text { ciência }\end{array}$ & 1997 & $\begin{array}{l}\text { Primeiro Centro } \\
\text { Ciência Viva } \\
\text { em Portugal, } \\
\text { numa rede de } \\
20 \text { centros de } \\
\text { ciência }\end{array}$ & $\begin{array}{l}\text { Agência Na- } \\
\text { cional Cultu- } \\
\text { ra Científica } \\
\text { e Tecnológica } \\
\text { (Ciência Viva), } \\
\text { Associação } \\
\text { Divulgação } \\
\text { Ciência e } \\
\text { Tecnologia } \\
\text { (ADCT) }\end{array}$ & $\begin{array}{l}\text { Agência Na- } \\
\text { cional Cultu- } \\
\text { ra Científica } \\
\text { e Tecnológica } \\
\text { (Ciência Viva), } \\
\text { Univ. Algarve, } \\
\text { C.M. Faro, } \\
\text { C.M. Albu- } \\
\text { feira }\end{array}$ \\
\hline $\begin{array}{l}\text { Oceanário de } \\
\text { Lisboa }\end{array}$ & $\begin{array}{l}\text { Aquário } \\
\text { moderno }\end{array}$ & 1998 & $\begin{array}{l}\text { Exposição Mun- } \\
\text { dial sobre o mar } \\
\text { "Expo 98” (Lis- } \\
\text { boa) para cele- } \\
\text { brar os } 500 \text { anos } \\
\text { da viagem de } \\
\text { Vasco da Gama } \\
\text { para a Índia }\end{array}$ & \begin{tabular}{|l|} 
Governo \\
Português
\end{tabular} & $\begin{array}{l}\text { Fundação } \\
\text { Oceano Azul } \\
\text { (Sociedade } \\
\text { Francisco } \\
\text { Manuel dos } \\
\text { Santos) }\end{array}$ \\
\hline
\end{tabular}

Tabela I. Identificação e características gerais de museus de Portugal continental relacionados com a biodiversidade marinha, escolhidos como exemplos neste capítulo. 


\section{Agradecimentos}

O primeiro autor (Bruno Pinto) teve o apoio da Fundação para a Ciência e Tecnologia (FCT), através do financiamento concedido ao MARE (UID/ MAR/04292/20 I 3) e uma bolsa de pós-doutoramento (SFRH/BPD/ I I 2 I I 9/2015). Este trabalho foi desenvolvido no âmbito da COST Action (ISI403-Oceans Past Platform) suportada pela COST (European Cooperation in Science and Technology). Os autores agradecem, também, a Cristina Brito (CHAM- Universidade Nova de Lisboa), a Paula Leandro e Maria José Pitta Groz (aquário Vasco da Gama), a Patrícia Filipe, Matilde Teixeira e Patrícia Jesus (Oceanário de Lisboa) e a José Lino Costa e Henrique Cabral (Faculdade de Ciências Universidade de Lisboa).

\section{Referências}

AMARAL, Ana Rita; MARTINS, Maria do Rosário; MIRANDA, Maria Arminda. O contexto museológico da antropologia na Universidade de Coimbra: Uma síntese histórica (I772-1933). In: História da Ciência na Universidade de Coimbra 1772-1933 edits. Carlos Fiolhais et alii. Coimbra: Imprensa da Universidade, p. 129-166, 2013.

AMORIM, Inês. Homens da Terra ou Homens do Mar - um percurso historiográfico. In: Culturas Marítimas em Portugal. Lisboa: Âncora editora, 2008.

AMORIM, Inês. Que espaço para uma abordagem do mar pelas Ciências Sociais e Humanas? In: Mar Português. Conhecimento, valorização e desenvolvimento. Faro: Universidade do Algarve, p. I73-188, 2012.

ANDRADE, Pedro de (coor.). Museus, públicos e literacia científico-tecnológica. Lisboa: Colibri, 20 I0.

ARGOS. Revista do Museu Marítimo de Ílhavo. Ílhavo: Museu Marítimo de Ílhavo, $\mathrm{n}^{\circ} \mathrm{I}, 2013$.

ATHIAS, Mark. A Sociedade Portuguesa de Ciências Naturais (notas históricas). Actas do I Congresso Nacional de Ciências Naturais. In: Bulletin de la Société Portugaise de Sciences Naturelles, Tome XIII, Supl. I, Livro I, v-xvii. Ed. Costa, F. IAC, Lisboa. 343 pp., 1942.

BASTO, A. de Magalhães. Memória Histórica da Academia Politécnica do Porto, precedida de Memória sobre a Academia Real da Marinha e Comércio pelo conselheiro Abreu Cardoso Machado. Porto: Universidade do Porto, 1937.

BRIGOLA, João Carlos. Colecções, Gabinetes e Museus em Portugal no Século XVIII. Lisboa: FCT Fundação Calouste Gulbenkian, 2003.

BRIGOLA, João Carlos. Os viajantes e o 'livro dos museus'. Porto: Dafne Editora, 2010. 
BRUNNER, Bernd. The Ocean at Home. An Illustrated History of the Aquarium. Princeton Architectural Press, New York, 2003.

CABRAL, Clara Maria Ferreira Bertrand. Património Cultural Imaterial - Proposta de Uma Metodologia de Inventariação. Lisboa: Universidade Técnica de Lisboa, 2008.

CAMACHO, Clara Frayão. Redes de Museus e credenciação. Uma Panorâmica Europeia. Casal de Cambra: Caleidoscópio, 2015.

CARNALL, Mark; ASHBY, Jack, ROSS, Claire. Natural history museums as provocateurs for dialogue and debate. Museum Management and Curatorship. London: Routledge, vol. 28 (I), p. 55-7I, 20 I3.

CARVALHO, Catarina Caprichoso. Gestão de Coleções do Museu de História Natural da Universidade do Porto. Porto: Relatório final de estágio apresentado à Faculdade de Ciências da Universidade do Porto, 2014.

CASEIRO, Carlos. A casa grande do mar. Aquário Vasco da Gama 1898-1998. Estar Editora,A.V.G. 139 pp., 1998.

CENTRO CIÊNCIA VIVA ALGARVE. Relatório de actividades 1998. Centro Ciência Viva Algarve, 1998.

CENTRO CIÊNCIA VIVA ALGARVE. Relatório de actividades 1999. Centro Ciência Viva Algarve, 1999.

CENTRO CIÊNCIA VIVA ALGARVE. Relatório de actividades 20 I I. Centro Ciência Viva Algarve, 201 I.

CERÍACO, Luís Miguel Pires. A evolução da zoologia e dos museus de história natural em Portugal. Évora: Universidade de Évora, 2014.

CERÍACO, Luís Miguel Pires; BRIGOLA, João Carlos Pires; DE OLIVEIRA, Paulo. Os monstros de Vandelli e o percurso das colecções de História Natural do século XVIII. In: História da Ciência Luso-Brasileira. Coimbra entre Portugal e o Brasil. Coimbra: Universidade Coimbra, pp.121 - I32, 2013.

CHAPPÉ, François. Histoire, mémoire, patrimoine. Du discours idéologique à l'éthique humaniste. Rennes: PUR, 2010.

CHOFFAT, Paul. Albert Arthur Alexandre Girard: Memória apresentada à Academia das sciencias de Lisboa, Volume 2, pp. 86-96.Academia das sciencias de Lisboa, Lisboa. 96 pp., 1916. 
COSTA,António Celestino. $O$ aquário Vasco da Gama: Estação de Biologia Marítima. Relatório referente aos anos de 1913 a 1917, apresentado na sessão de 21 de novembro de 1917. Lisboa: Imprensa da Livraria Ferin. 36 pp., 1918.

COSTA, António Celestino. $O$ aquário Vasco da Gama: Estação de Biologia Marítima. Relatório apresentado à Comissão Oceanográfica na sessão de I de dezembro de 1921 e referente aos anos de 1917 a 1921. Lisboa:Oficinas Gráficas Biblioteca Nacional. 17 pp., 1922.

COSTA, António Firmino; PALMA, Cristina; ÁVILA, Patrícia. Scientific Culture and modes of relating to science, in A.F. Costa, F.L. Machado and P. Ávila, Knowledge and Society Portugal in the European Context, vol. II, Oeiras, Celta, pp. 59- 80, 2009.

COSTELLO, Mark; BOUCHET, Philippe; BOXSHALL, Geoffrey; FAUCHALD, Kristian, et al. Global Coordination and Standardisation. Marine Biodiversity through the World Register of Marine Species (WoRMS) and Related Databases. PLOS ONE 8(I), 2013.

CUNHA, Maria José. As colecções Antropológicas do Museu de História Natural da Faculdade de Ciências da Universidade do Porto. In Actas do I Seminário de Investigação em Museologia dos Países de Língua Portuguesa e Espanhola. Porto: Universidade do Porto, Volume I, p. 259-268, 2010.

CUNHA, Maria José.As Colecções de Arqueologia e Antropologia do Museu de História Natural da Universidade do Porto. In: Series Ibero-americanas de Museologia. Porto: Universidade do Porto,Volume 6, p. I53-I62, 2012.

DAMASCENO, Joana. Museus para o Povo Português. Coimbra: Imprensa da Universidade de Coimbra, 2010.

DELICADO, Ana. Os museus e a promoção da cultura científica em Portugal. Sociologia, problemas e práticas, n. ${ }^{\circ}$ 5I, p. 53-72, 2006.

DELICADO, Ana. Produção e reprodução da ciência nos museus portugueses. Análise Social, vol. XLIII (I. $\left.{ }^{\circ}\right)$, p.55-77, 2008.

DELICADO, Ana. Museus, divulgação da ciência e cultura científica em Portugal. Museologia.pt, 4, I44-I65, 2010.

DIÁRIO ILUSTRADO. O aquário. Diário llustrado 2 I Maio I898: 2, 1898.

DUARTE,Adelaide Manuela da Costa. O Museu Nacional da Ciência e da Técnica (197I-1976). Coimbra: Imprensa da Universidade de Coimbra, 2007. 
FIOLHAIS, Carlos. História da Ciência em Portugal. Lisboa: Gradiva, 2013.

FOUNDATION FOR SCIENCE AND TECHNOLOGY (FCT) (20I5). Establishing Portugal as a global reference for research and innovation (Pp. 2-3). Fundação para a Ciência e Tecnologia. Disponível em: https://www.fct.pt/documentos/Brochura_FCT_web.pdf.

FUNDAÇÃO OCEANO AZUL. A fundação. Fundação Oceano Azul, 20 I8. Disponível em: https://www.oceanoazulfoundation.org/pt-pt/

GARCIA, José Luís; RAMALHO, Joana; SILVA, Pedro Alcântara. Os Públicos da Rede Nacional de Centros Ciência Viva - Relatório Final. Instituto de Ciências Sociais, Universidade de Lisboa para a Rede Nacional de Centros Ciência Viva, 2016.

GARRIDO, Álvaro. Ser do Mar: O Museu Marítimo de Ílhavo como lugar de projecto Drassana, n. 22, p. I40-I47, $20 \mid 4$.

GARRIDO, Álvaro;ALVES, Francisco, coor. Octávio Lixa Filgueiras. Arquitecto de Culturas Marítimas. Lisboa: Âncora Editora, 2009.

GARRIDO, Álvaro; LOPES, Ana Maria. Sala da Ria. Catálogo da exposição permanente. Museu Marítimo de Ílhavo. Ílhavo: Museu Marítimo de Ílhavo, 2004.

GARRIDO, Álvaro; LEBRE, Ângelo. Museu Marítimo de Ílhavo. Um Museu com História. Lisboa: Âncora Editora/Museu Marítimo de Ílhavo, 2007.

GIL, Fernando Bragança. University museums. University. Intensifying Support For and Increasing Audiences in University Museums and Collections. Museologia - an international journal of museology,Vol. 2, Nr. I-2 (Special issue), p. I-7, 2002.

GIL, Fernando Bragança. Museus Universitários, sua especificidade no âmbito da Museologia. In: Colecções de ciências físicas e tecnológicas em museus universitários, coor. A.C. da Silva e A. Semedo. Porto: Faculdade de Letras do Porto, p. 33-54, 2005.

GIRARD, Alberto. Relatório sobre o estado actual do Aquário Vasco da Gama. Direcção Geral da Marinha, processo 24, 3 I/01/1907. Arquivo Geral da Marinha, Lisboa, 1907.

GRANADO, António; MALHEIROS, José Vitor. Cultura científica em Portugal: Ferramentas para perceber o mundo e para aprender a mudá-lo. Lisboa: Fundação Francisco Manuel dos Santos, 2015.

KISLING, Vernon N. Zoo and Aquarium History: Ancient Animal Collections to Zoological Gardens. CRC Press, Boca Raton. 4 I 5 pp, 200 I. 
KOFOID, Charles Atwood. The Biological Stations of Europe. United States Bureau of Education Bulletin 4, 360 pp, 1910.

LEANDRO, Paula.Aquário Vasco da Gama, Um dos primeiros aquários em todo o mundo. Anais do Clube Militar Naval. Lisboa, Academia de Marinha, I33: 70573I, 2003.

LEAL, João. Etnografias Portuguesas (1870-1970): Cultura Popular e Identidade Nacional. Lisboa: Publicações Dom Quixote, 2000.

MARÍA BOLANOS, ed.. La Memoria del mundo, Cien años de museologia 19002000. Gíjón: Ediciones Trea, S.L., 2002.

MARTINS, Nuno Gomes. OfWorld Representation:International Exhibitions and the Expo'98. Cadernos do Arquivo Municipal. Series 2 (5), p. 357-382, 20 I6. Disponível em: http://arquivomunicipal.cm-lisboa.pt/fotos/editor2/Cadernos/2serie/ cad5/varia02.pdf.

MONTEIRO, Marisa L.; BERNARDO, Luís M.; ARAÚJO, José M. O Museu de Ciência da Universidade do Porto: colecções de ciências exactas da Faculdade de Ciências. In Coleções Científicas Luso-Brasileiras: patrimônio a ser descoberto. Rio de Janeiro: Museu de Astronomia e Ciências Afins - MAST/MCT, p. 2 I l-230, 2010.

MORRIS, Benjamin. 'Not just a place': cultural heritage and the environment. In: Heritage, Memory \& Identity ed. Helmut Anheier e Y.Raj Isar, London: Sage, p. I24I36, $201 \mathrm{I}$.

MUSEU DO MAR. Museu do Mar Rei D. Carlos, 20 I8. Disponível em: http:// www.cm-cascais.pt/museumar/home.html

NUNES, Maria de Fátima. The History of Science in Portugal (1930-1940): The sphere of action of a scientific community. E- JPH,Vol. 2 number 2, Winter p.I17, 2004.

OCEANÁRIO DE LISBOA. EMAS 20I I. Declaração Ambiental, 20I I. Disponível em: https://www.oceanario.pt/content/files/emas_20II_2.pdf

OCEANÁRIO DE LISBOA. EMAS 20I4. Declaração Ambiental, 20I4. Disponível em: https://www.oceanario.pt/content/files/da_emas_20l4.pdf

OCEANÁRIO DE LISBOA. EMAS 20I5. Declaração Ambiental, 20I 5. Disponível em: https://www.oceanario.pt/content/files/emas_2015_oceanario_de lisboa. pdf 
PARQUE EXPO'98. Exposição Mundial de Lisboa de 1998. Relatório. Lisboa: Parque Expo'98, 1999.

PERALTA, Elsa. Memória do mar. Património marítimo e (re)imaginação identitária na construção do local. In Patrimónios e Identidades. Ficções contemporâneas. Oeiras: Celta, 2006.

PERALTA, Elsa. Museus e Comunidades: Uma Ensaio Antropológico a Propósito da História do Museu Marítimo de Ílhavo. In Museu Marítimo de Ílhavo: Um Museu com História. Lisboa: Âncora Editora/Museu Marítimo de Ílhavo, p. 21 9-236, 2007.

PERALTA, Elsa. Public silences, private voices: Memory games in a maritime heritage complex. In Heritage and Identity. Engagement and Demission in the Contemporary World. London and New York: Routledge, p. I 05- I I 6, 2009.

PINTO, Bruno. Historical connections between early marine science research and dissemination: the case-study of aquarium Vasco da Gama (Portugal) from late 19th century to mid-20th century. ICES Journal of Marine Science Volume 74 (6): I522-I530, 2017.

PINTO, Bruno. 1998, celebrating oceans in Lisbon Expo'98: World exhibitions and science communication. Public Understanding of Science Volume 27(4), 490-494, 2018. Disponível em: http://journals.sagepub.com/doi/ full/I0.I I 77/09636625I 7743375 .

PINTO, Bruno; COSTA, José Lino. What are the practitioners'views about past marine science communication to the public? An example from Portugal. Regional Studies of Marine Science Volume I8: 27-34, 2018.

PITTA E CUNHA, Tiago. Portugal e o mar. À redescoberta da geografia. Ensaio da Fundação Francisco Manuel dos Santos, 20II.

PIRES, Catarina Pereira; PEREIRA, Gilberto Gonçalves. Museu da Ciência da Universidade de Coimbra: valorização de um patrimônio científico secular. In Coleções Científicas Luso-Brasileiras: patrimônio a ser descoberto, Organização: Marcus Granato e Marta C. Lourenço. Rio de Janeiro: Museu de Astronomia e Ciências Afins - MAST/MCT, I85-2I0, 2010.

PÓVOAS, Liliana; LOPES, César; MELO, Ireneia, CORREIA, Ana I.;ALVES, Maria Judite. $O$ museu nacional de história natural - uma história atribulada e uma questão em aberto. Estudos do Quaternário, I4, APEQ, Braga, p. I05-II3, 2016. http://www.apeq.pt/ojs/index.php/apeq.

POSSANTE, Manuel José. Relatório do Presidente do Conselho de Administração do Aquário Vasco da Gama- Estação de Biologia Marítima. 38 pp, 1949. 
RAMALHO,Alfredo Magalhães. Relatório do Dr. Magalhães Ramalho para o Presidente do Conselho de Administração do Aquário Vasco da Gama- Estação de Biologia Marítima, Lisboa. 20 pp, 1942.

RAMOS, Rui. Capítulo V: O fracasso do reformismo liberal (I890-1910). In: História de Portugal, pp. 549-572. Ed. by R. Ramos, B.V. Monteiro and N.G. Sousa. Esfera dos Livros, Lisbon. 976 pp, 2012.

ROLLO, Maria Fernanda; QUEIROZ, Maria Inês; BRANDÃO, Tiago. The sea as science: ocean research institutions and strategies in Portugal in the twentieth century (from the First Republic to democracy). História, Ciências, Saúde- Manguinhos, 2 I (3): I- I9, 2014.

SALDANHA, Luís. King Carlos of Portugal, a Pioneer in European Oceanography. In: Oceanography: the Past, pp. 606-6I3. Ed. By M. Sears, and D. Merriman. Springer-Verlag, New York. 812 pp, 1980.

SALDANHA, Luís. King Carlos de Bragança, the Father of the Portuguese Oceanography. In: One Hundred years of Portuguese Oceanography, in the footsteps of King Carlos de Bragança, pp. 19-38. Ed. by L. Saldanha, and P. Ré. Museu Nacional de História Natural. 453 pp, 1997.

SALDANHA, Ana Rita; NUNES, Maria de Fátima; DIAS, José Pedro Sousa. Práticas, redes e produções científicas dos naturalistas do Museu Bocage na Europa entre guerras (19|4-|45). O Património Documental do Museu Nacional de História Natural e da Ciência da Universidade de Lisboa (MUHNAC-UL). In Perspetivas_sobre Construir_Ciência_-_Construir_o_Mundo. Aveiro: Universidade de Aveiro, p. 266-272, 2015.

SALGADO, Maurício Matos; MARANDINO, Martha. O mar no museu: um olhar sobre a educação nos aquários. História, Ciências, Saúde-Manguinhos [online] 21 (3), p .867-882, $20 I 4$.

SALGUEIRO, Ângela. Laboratórios universitários - espaços de ciência na transição da Monarquia para a República. In Espaços e Actores da Ciência em Portugal (XVIII-XX). Casal de Cambra: Caleidoscópio, p. 65-74, 2014.

SANCHO QUEROL, Maria Lorena. A função social do Património Marítimo Português. Cadernos de sociomuseologia. Lisboa, vol. 35, p. 7-230, 2009.

SARMENTO, Clara. Cultura Popular Portuguesa. Práticas, Discursos e Representações. Porto:Afrontamento, 2008.

SANTOS, Anabela. Um Museu para as nossas Nefertitis. Campus U. Porto. Revista da Universidade do Porto. $n^{\circ}$ 0. Porto, p. 28-3I, 2016. 
SEMEDO, Alice. Estratégias museológicas e consensos gerais. In Museos do Eixo Atlántico. Porto,Vigo: s.ed., p.5-32, 2004.

SEMEDO, Alice; NASCIMENTO, Elisa Noronha; CENTENO, Rui (coord). Seminário internacional o futuro dos museus universitários em perspetiva. Porto: Universidade do Porto, Faculdade de Letras, 2014.

SERVIÇOS MUNICIPALIZADOS ÁGUA E SANEAMENTO (SMAS). A obra do Dr.Alfredo Ramalho, pioneiro da oceanografia. SMAS, 12 pp., 2002.

SERRANO MARTÍNEZ, Javier. Ciencia+Tecnologia+sociedad+museos= Cómo conseguir que el futuro se parezca a lo que esperamos. Gijón: Ediciones Trea, S. L., 2013.

SILVA, A. O aquário Vasco da Gama. Imprensa Nacional, Lisboa. 4 I pp, 1901.

SIMÕES, Carlota; CASALEIRO, Pedro; MOTA, Paulo Gama. O Museu da Ciência: uma colecção científica do século das Luzes. In História da Ciência na Universidade de Coimbra 1772-1933. Coimbra: Imprensa da Universidade, p.I I7- I 28, 2013.

SOCIEDADE DE GEOGRAFIA. À comissão da exposição das pescarias e outros. Quarto Centenário da Descoberta da Índia: Annaes da Comissão Central Executiva. Correspondência e Actas. Vol.VII-XI (pp. 89-95). Imprensa Nacional: Lisboa. 102 pp., 1897.

SOCIEDADE DE GEOGRAFIA. Sessão de 8 de Novembro 1897.Actas das sessões da Sociedade de Geografia de Lisboa 1894-I899. Vol. XIV-XV (pp. 6I-65). Imprensa Nacional: Lisboa. I 19 pp., 1899.

STRASSER, Bruno. Laboratories, Museums, and the Comparative Perspective: Alan A. Boyden's Quest for Objectivity in Serological Taxonomy, 1924-1962. Historical Studies in Natural Sciences, 40 (2), p. I49-182, 2010.

TELES, Américo. Guia Prático de preparação de Algas Marinhas. Uma colecção do Museu Marítimo de Ílhavo 1986. Ílhavo: Museu Marítimo Ílhavo, 2012.

UNITED NATIONS EDUCATIONAL, SCIENTIFIC AND CULTURAL ORGANIZATION (UNESCO). Global Ocean Science Report-The current status of ocean science around the world (Pp. I08-I I0). UNESCO Publishing, Paris, 2017.

WAGENSBERG, Jorge. The "total" museum, a tool for social change. Historia, Ciencias, Saúde. Manguinhos [online]. vol. I 2, suppl., p. 309-32I, 2005. 